\title{
Population Density Prediction of Wuhan City Based on the Linear Regression Model
}

\author{
Yu Xia, Cheng Wang* \\ School of Mathematics and Economics, Hubei University of Education, \\ Wuhan 430205, P. R. China \\ *Corresponding Author: wangc80@163.com
}

\section{Keywords: Population density; Linear regression model; Main influencing factors}

\begin{abstract}
In this paper, the problem of population density prediction of Wuhan City is studied, and a prediction model based on linear regression model is presented. Then, considering three main factors, i.e., GDP, employment quantity and completed area of housing construction, which affect the population density of Wuhan City, an empirical analysis is given according to the data information from statistical yearbook of Wuhan City from 2010 to 2014. The result provides valuable decision references for the population management department.
\end{abstract}

\section{Introduction}

With the rapid economic development of Optics Valley, as GDP accounts for $70 \%$ of the region in Wuhan, the population has jumped to 1 million 500 thousand, and the current GDP in Optics Valley accounted for half of Wuhan, and the proportion of the future will be further expanded. Today, Optics Valley is established by the State Council as a public entrepreneurship innovation base, optoelectronics information, biomedicine, high-end equipment manufacturing, new energy, environmental protection and modern service industry has become a strategic core industry. Huge economic strength and plenty of people [1-4].

In order to predict the area suitable for living population, according to the situation in Wuhan, the statistical data collection factors may have an impact on the population density of the area, such as data in Wuhan in recent years the average annual temperature, employment quantity, completed area of housing construction, the completion of the new high-tech industry development, the total production value of Road area throughout the year, GDP, then need to establish a mathematical model of quantitative analysis of these factors on the impact of population density, so as to determine the factors of several main influencing factors. Finally, based on these main effects, establish the relation model between them and the population density. considering three main factors, i.e., GDP, employment quantity and completed area of housing construction [5-7], which affect the population density of Wuhan City, this paper presented a prediction model based on linear regression model $\mathrm{i}$, and then gave an empirical analysis according to the data information from statistical yearbook of Wuhan City from 2010 to 2014.

\section{The Model}

The linear regression model between the three main influencing factors of population density and urban population with the population density of $y$ and the annual GDP of Wuhan, the employment quantity and the completed area of housing construction is as follows:

$$
y=\beta_{0}+\beta_{1} x_{1}+\beta_{2} x_{2}+\beta_{3} x_{3}
$$

Using the least square method to estimate the parameter $\beta$ in the model, the squared error of this set of data is

$$
Q(\beta)=(y-x \beta)^{T}(y-x \beta)
$$

Find $\beta$ to minimize $Q(\beta)$ and obtain the least squares estimate of $\beta$, denoted $\hat{\beta}$, to be introduced 
$\hat{\beta}=\left(X^{T} X\right)^{-1} X^{T} Y$

Replacing $\hat{\beta}$ with the original model yields the estimated value of $y$

$\hat{y}=\hat{\beta}_{0}+\hat{\beta}_{1} x_{1}+\hat{\beta}_{2} x_{2}+\hat{\beta}_{3} x_{3}$

The fit of this set of data is

$\hat{Y}=X \hat{\beta}$

We can draw the following results:

(1) $\hat{\beta}$ is a linear unbiased minimum variance estimate of $\beta$, which means that $\hat{\beta}$ is a linear function of $Y ; \hat{\beta}$ has the expectation equal to $\beta$; and $\beta$ has the least variance in the linear unbiased estimate of $\hat{\beta}$.

(2) $\hat{\beta}$ obeys normal distribution

$\hat{\beta} \sim N\left(\beta, \sigma^{2}\left(X^{T} X\right)^{-1}\right)$

(3) Square sum of residuals $Q, E Q=2 \sigma^{2}$, and

$\frac{Q}{\sigma^{2}} \sim \chi^{2}(2)$

This results in an unbiased estimate of $\sigma^{2}$

$s^{2}=\frac{Q}{2}=\hat{\sigma}^{2}$

where $s^{2}$ is the residual variance (residual variance) and $\mathrm{s}$ is the residual standard deviation.

(4) The total square and $S=\sum_{i=1}^{n}\left(y_{i}-\bar{y}\right)^{2}$ decomposition, where

$$
\begin{aligned}
& S=Q+U, \\
& U=\sum_{i=1}^{3}\left(y_{i}-\bar{y}\right)^{2},
\end{aligned}
$$

where $Q$ is the sum of squared residuals, which reflects the effect of random error on $y, U$ is called the sum of squares of the regression, reflecting the influence of pairs of independent variable on $y$.

Test of the hypothesis of regression model. An indicator of the degree of correlation between $y$ and $x_{1}, \cdots, x_{m}$, as defined by the ratio of the sum of squares of the regression to the sum of the squares

$$
R^{2}=\frac{U}{S}
$$

where $R \in[0,1]$ is called the correlation coefficient, $R$ is larger, $y$ is more closely related to $x_{1}, x_{2}, \cdots, x_{m}$.

Generally, $R$ is greater than 0.8 (or 0.9 ) that the correlation holds.

\section{Analysis of Population Density in Wuhan City}

Through the collation of the data collected, the data information of population density and annual output value of Wuhan, the employment quantity and completed area of housing construction is listed in Table 1.

The establishment of population density and annual output value of Wuhan City, employment quantity and the completed area of housing construction can be regarded as a multivariate linear regression model. By using the software of SPSS to solve this model, we can get the results as follows.

Correlation coefficient: 


\begin{tabular}{|c|c|c|c|c|c|}
\hline \multirow{2}{*}{\multicolumn{6}{|c|}{$\hat{\beta}_{0}=7690.518$}} \\
\hline & & & & & \\
\hline \multicolumn{6}{|l|}{$\hat{\beta}_{1}=-16.608$} \\
\hline \multicolumn{6}{|l|}{$\hat{\beta}_{2}=0.021$} \\
\hline \multicolumn{6}{|l|}{$\hat{\beta}_{3}=0.212$} \\
\hline \multirow{4}{*}{\multicolumn{6}{|c|}{$\begin{array}{l}\text { F value: } \\
F=8.284 \\
\text { Correlation coefficient: } \\
R^{2}=0.926>0.9\end{array}$}} \\
\hline & & & & & \\
\hline & & & & & \\
\hline & & & & & \\
\hline \multicolumn{6}{|c|}{ Table 1. The data of the main influencing factors } \\
\hline Factors & 2010 & 2011 & 2012 & 2013 & 2014 \\
\hline $\begin{array}{l}\text { Population density } \\
\left(\text { person } / \mathrm{km}^{2}\right)\end{array}$ & 984 & 985 & 1180 & 1191 & 1203 \\
\hline $\begin{array}{l}\text { Employment quantity } \\
\text { (million) }\end{array}$ & 483 & 498 & 506.4 & 522.24 & 530.44 \\
\hline $\begin{array}{l}\text { Completed area of } \\
\text { housing construction } \\
(10,000 \text { square } \\
\text { meters })\end{array}$ & 5664.39 & 8114.17 & 9223.5 & 10103.98 & 10223.95 \\
\hline Annual output value & 5565.93 & 6762.2 & 8003.82 & 9051.27 & 10069.48 \\
\hline
\end{tabular}

These results show that the population density and the linear relationship between the three main factors set up, so we can draw the population density and annual output value of Wuhan, the number of employees and the completion of the area between the building is expressed as

$y=7690.518-16.608 x_{1}+0.021 x_{2}+0.212 x_{3}$.

According to the statistics in Table 1, the GM $(1,1)$ model [1] predicts that the completed area of housing construction for 2017 will be 139,820,900 square meters, with 5,694,700 employees and an annual gross product value of 1,393,307 million yuan, which will be substituted into $y=7690.518-16.608 x_{1}+0.021 x_{2}+0.212 x_{3}$. The population density (unit: person / square kilometer) is 1481.46697 , and the population of the area is

$y=87.1915 \times 1481.46697 \approx 129171$.

\section{Model Analysis and Testing}

In order to test the rationality and feasibility of the model, according to the relevant literature and data collected from the Internet, the following test model.

Test area size. CAD mini-drawing can measure the picture is the area, the picture into the CAD mini-drawing and select $\mathrm{n}$ points along the area border, the measurement area of 218358.

Then measure the map is the length of $2 \mathrm{~km}$ on the ruler of 100, after conversion, get the area of this area

$S=4 \times 22.8358=91.3432 \mathrm{~km}^{2}$.

This polygon area formula with any large difference, because it is artificial point, the picture can not be enlarged too much in the software, leading to point is not accurate, there will be some error.

The population test. In this paper, the GM $(1,1)$ model is used to predict the three major factors of Wuhan's annual GDP, the number of employees and the completed area of housing construction. The predicted values of three factors in 2017 are obtained and substituted into the established multiple linear regression model. We use the GM $(1,1)$ model to predict the population density of Wuhan in 2010-2015 (the data in Table 1 are substituted into the gray system software developed 
by Nanjing University of Aeronautics and Astronautics). As can be seen from the figure, the relative errors are all greater than $90 \%$, with a high degree of credibility. The predicted population density is 1345.610971 (person / km 2), which still lags behind the 1481.46697 (person / km 2) Within acceptable range. Since only the first three factors affecting the population density are selected, there may be some error in the model. It would be more accurate to build a multiple linear regression model if we could take a few more factors.

Improve idea: Since the collected data are data from Wuhan, the status of Wuhan's development can not be directly equated with the development of the Donghu Hi-tech Zone to which the region belongs. In order to make the model more reasonable, the data in the paper will be more accurate for the corresponding data of Donghu Hi-tech Zone.

\section{Conclusions}

In this paper, we established a multiple linear regression model of population density to predict the population density for Wuhan City. The population density regression model established in this paper is suitable for studying the relationship between one random variable and other variables over time. Therefore, it can be popularized and applied to deal with economic, environmental and ecological data, such as the pricing of products, the determination of factory water turbidity and the analysis of air pollution level.

\section{Acknowledgments}

This work is supported by the 2017 Excellent Youth Project (Project Leader: Cheng Wang) of Hubei Provincial Department of Education.

\section{References}

[1] Y. Gao: Simulation of Downscaling of County Population Density Based on GIS Data (China's Population, Resources and Environment 2017).

[2] Wuhan Statistical Yearbook on http://www.whtj.gov.cn/

[3] Z.Q. Luo: Derivation and Application of Arbitrary Polygon Area Formula (University of Electronic Science and Technology of China, Chengdu 2005).

[4] C.J. Rao, M. Goh, Y. Zhao and J.J. Zheng: Location selection of sustainability city logistics centers, Transportation Research Part D: Transport and Environment 36 (2015) 29-44.

[5] M. Grove: Population density, mobility, and cultural transmission, Journal of Archaeological Science 74 (2016) 75-84.

[6] C.J. Rao, X.P. Xiao, M. Goh, J.J. Zheng and J.H. Wen: Compound mechanism design of supplier selection based on multi-attribute auction and risk management of supply chain, Computers \& Industrial Engineering 105 (2017) 63-75.

[7] M.M. Rahman: Do population density, economic growth, energy use and exports adversely affect environmental quality in Asian populous countries? Renewable and Sustainable Energy Reviews 77 (2017) 506-514. 